Advanced Computing: An International Journal ( ACIJ ), Vol.3, No.1, January 2012

\title{
A NEW TREND FOR E-LEARNING IN KSA USING EDUCATIONAL CLOUDS
}

\author{
Abdullah Alshwaier, Ahmed Youssef and Ahmed Emam \\ Department of Information Systems, King Saud University, Riyadh, KSA \\ Abdullah-shwaier@hotmail.com, ahyoussef@ksu.edu.sa, aemam@ksu.edu.sa
}

\begin{abstract}
Cloud computing provides a shared pool of computing resources that can be rapidly and elastically provisioned and released based on users' demand to serve a wide and constantly expanding range of information processing needs. Due to its tremendous advantages this technology is maturing rapidly and is being adopted in many applications including government, business, and education. In this paper, we study how cloud computing can benefit e-learning education in KSA. We discuss the cloud computing educational environment and explore how universities and institutions may take advantage of clouds not only in terms of cost but also in terms of efficiency, reliability, portability, flexibility, and security. We present several case studies for educational clouds introduced by popular cloud providers which reflect the increasing interest in this new trend. We also discuss future challenges to cloud education.
\end{abstract}

\section{KEYWORDS}

Cloud Computing, E-learning, Online Learning, Web-based Learning, Utility Computing, Learning Management Systems, Distance Learning, Education Systems.

\section{INTRODUCTION}

Education is an important component of life because it equips us with all that is needed to make our dreams come true. One of the most promising paradigms for education is e-learning. It is commonly referred to the intentional use of networked information and communications technology (ICT) in teaching and learning. Some other terms are also used to describe this mode of teaching and learning including online learning, virtual learning, distributed learning, network and web-based learning. Since the last decade there is a growing interest in e-learning from several directions. Distance education programs see it as a logical extension of their distance education activities. Residential campus-based educational organizations as well see elearning as a way of improving access to their programs and also as a way of tapping into growing niche markets [42-45]. The growth of e-learning is directly related to the increasing access to ICT, as well as its decreasing cost. The capacity of ICT to support multimedia resource-based learning and teaching is also relevant to the growing interest in e-learning. Growing numbers of teachers are increasingly using ICT to support their teaching. Educational organizations see advantages in making their programs accessible via a range of distributed locations, including on campus, home and other community learning or resource centres. Thanks to ICT, the dream of learning anywhere and at anytime has become true. Despite this level of interest in e-learning, it has many constraints and limitations. The main obstruction to the growth of e-learning is the lack of access to the necessary technology infrastructure, for without it there can be no e-learning. Poor or insufficient technology infrastructure can cause more damage than good to teachers, students and the learning experience [44]. While the costs of the hardware and software are falling, often there are other costs that have not been factored into the deployment of e-learning ventures. The most important of these include the costs of infrastructure support and its maintenance and the appropriate training of staff to enable them to make the most of the technology [44]. 
Cloud Computing is a new paradigm that provides efficient network login to an appropriate pool of computing resources which can be provided and released with just nominal assiduity and service providers reciprocity [3,5,19,46-50,54-56]. The resources can be network servers, applications, platforms, infrastructure segments and services. Cloud computing delivers services autonomously based on demand and provides sufficient network access, data resource environment and effectual flexibility. This technology is used for more efficient and costeffective computing by centralizing storage, memory, computing capacity of PC's and servers. With the tremendous advantages of cloud computing, we expect this technology to revolutionize the field of e-learning education. Cloud computing applications provide flexibility for all educational universities, schools and institutions. The cloud platform in institutions' campuses provides effective infrastructure and deployment model for their dynamic demands. The benefits of cloud computing can support education institutions to resolve some of the common challenges such as cost reduction, quick and effective communication, security, privacy, flexibility and accessibility $[1,2,4,6,7,15]$.

In this paper, we study how cloud computing can benefit e-learning education in KSA. We discuss the cloud computing educational environment and explore how universities and institutions may take advantage of clouds not only in terms of cost but also in terms of efficiency, reliability, portability, flexibility, and security. We present several case studies for educational cloud introduced by popular cloud providers which reflect the increasing interest in this new trend in education. We also discuss future challenges including risks and problems associated with cloud education. The rest of this paper is organized as follows: in section 2 we explore the current status of e-learning usability in KSA. In section 3 we give a brief overview on cloud computing and discuss the educational cloud computing environment. Section 4 presents case studies of educational clouds provided by the most popular cloud providers. Challenges associated with cloud computing education are discussed in section 5. Finally, section 6 concludes the paper.

\section{Current E-Learning in KSA}

E-learning can be defined as all forms of electronically supported learning and teaching. It intersects numerous fields of thought and practice such as training and education, learning and knowledge and technology. E-learning is essentially the computer and network-enabled transfer of skills and knowledge, which include applications and processes such as Web-based learning, computer-based learning, virtual education opportunities and digital collaboration. E-learning can be categorized into two main categories, synchronous and asynchronous [58]. With synchronous e-learning students can be involved in a course that meets online with the faculty member through streaming audio and video at a predetermined time. A major disadvantage of synchronous e-learning is the issue of having to meet at specific time, hence, time flexibility is lost. With asynchronous learning, a student can participate in the learning activities at the most suitable time for him or her but this also means that the faculty member will not be available for immediate replies. A set of tools called Learning Management Systems (LMS) is typically utilized with e-learning and there are many types of LMS. Some of LMS are commercial products and the most popular one is called Blackboard (http://www.blackboard.com) and others are open-source such as Moodle (http://moodle.org/). Many researchers developed several investigations last five years about the usability of e-learning in Kingdom of Saudi Arabia (KSA) and in following section we select some of those researches as a roadmap of Elearning utility.

Albalawi [57] stated that the use of information technology in distance learning, E-learning or Web-Based Instruction (WBI) could be one way to deal with the challenging situation in countries that provide technology access to all citizens. He mentioned that the role of the faculty in higher education across the world is changing as technology evolves. He mentioned that 
factors such as attitudes, incentives, support, training, policies, time and tenure problems can be oblique, inhibiting or encouraging faculty members in Saudi universities to participate in distance learning and e-learning. He raised the following questions in his study: What are the attitudes of the Saudi faculty toward WBI? How do the factors related to the barriers influence faculty participation in WBI? How do the factors related to incentives influence faculty participation in WBI? He stated that his research can help the Saudi universities conduct a comparison of what they are doing and what they could be doing to increase the involvement of their faculties in adopting distance-learning technology. He concluded that overall faculty attitudes toward WBI were positive. They believe that online courses are the future of higher education in Saudi Arabia. They also believe that WBI will improve students' learning, encourage students to be more interested in learning, be a good teaching tool because of gender segregation in the Saudi higher-education system and create a challenge for faculty. He also mentioned the main nine barriers for WBI and e-leaning in KSA which are lack of knowledge, lack of enough time to develop WBI, lack of clear WBI policies, lack of clear course ownership policies, lack of peer support, lack of technical support, lack of monetary incentive, lack of administrative support and lack of governmental support. Finally, he suggested several recommendations such as developing further studies to determine if there are other factors affecting the implementation of WBI at Saudi universities beyond his findings.

Mirza [58] stated that e-learning is a great option for many Saudi students who are interested in higher education from reputable international universities and who cannot travel to other countries due to family, financial and or employment obligations. However, old regulations at the Ministry of Higher Education (MOHE) have managed to find their way into the 21st century. The author gave an example for MOHE regulations, in order to approve a degree from any international university a student must present evidence that his/her time was dedicated to studying on a full-time basis while residing in the country where the degree was earned, (http://www2.mohe.gov.sa/accreditation/Acc_Requirements.aspx). Mirza mentioned that elearning in the developed world has become a great success because it provides students with the convenience and flexibility of studying at their own pace, time and cost. However, it is not free of drawbacks; he mentioned some drawbacks of e-learning such as high initial costs to setup, the on-going costs for maintenance, the fact that not all students are self-motivators, hence, they may easily fall behind and the inability to properly assess the performance of students who use the system. Mirza also stated that in 2007 Saudi Arabian-MOHE has established a National Center for e-Learning and Distance Learning (NCeDL) which aims to support in the creation of electronic educational material, and providing an electronic venue for faculty members of any local university to utilize in creating e-courses through its own LMS called JUSUR (http://www.elc.edu.sa/portal). He mentioned several public and private schools start to adopt e-learning system and a good number of Saudi schools and colleges have already moving towards the application of e-learning. Finally, he recommended establishing a set of new policies that allow students to take virtual online degrees.

Kamla [59] defined the Learning Management Systems (LMS) as an online system that allows users to share information and collaborate online and she mentioned that there is no specific definition for LMS because there are different viewed among different players depending on how many features and tools are opted to be incorporated. In particularly, LMS could be utilized by educational institutions as well as corporate ones with a major focus on managing the education process rather than merely delivering course and training materials electronically. The author stated that the main propose of her research is to find the relevant external variables that influence the instructors' acceptance of LMS. Kamla stated that the main critical factors that might influence the instructors' perceived ease of use and usefulness of LMS can be categorized by instructor, organization and technology factors. Instructor factors include self efficacy, attitude toward LMS, experience, teaching style and personal innovativeness, while organization factors include motivators, technology alignment, organization support, technical 
support and training. Technology factors include system quality, information quality and service quality. The author believed that she developed a theoretical model and empirical investigations to find out the main factors but qualitative studies such as case analysis or interviews might reveal some further insights on these factors.

Hend [60] evaluated the usability of JUSUR LMS; a leaning management system built based on METEOROUM's, the Malaysian Open University popular LMS. The main goals of JUSUR LMS were to provide teaching staff and students in the Saudi Higher Education with an online collaborative teaching and learning environment as well as promote the use of teaching and learning technologies. She mentioned that the purpose of her research is to present some findings of the usability of JUSUR. The research explored the first semester of the academic year 2008/2009 at the Information Technology Department at King Saud University thorough Web Applications Engineering course. Hend developed two standard questionnaires to evaluate the System Usability Scale (SUS) and User Satisfaction. The basic findings that the Students' usability survey revealed was that JUSUR LMS is easy to use and learn for students with advanced computer competency and the most significant problems were the malfunction of the search feature and the difficulty of downloading course materials. She believed that further usability studies needed to evaluate JUSUR using different variables such as users' computer competency, gender and major.

Hisham [61] stated that the selection procedure for LMS start by selecting and identifying user needs, choosing a range of products required by the user and verifying requirements, assessing the advantages and disadvantages of LMS, sorting products in terms of advantages and disadvantages, then determining the results and choosing the alternative best suited to the needs of the user. The author stated that about 1283 course out of 2336 courses offered in the first semester of the academic year 2009/2010 by JUSUR. He lunched two important questions in his research: what trends faculty members in Saudi universities to use LMS bridges and what are the obstacles to use system bridges from the viewpoint of faculty members in Saudi universities? The author concludes that there are positive trends from the members of the faculty towards the use of e-learning bridges. He also stated that the physical barriers from using JUSURE are college infrastructure, lack of the availability of computer equipments or internet service and the absence of direct technical support to faculty members and students before and during the use of the system. The personal barriers mentioned by the user are the fear of technology, community resistance to the operations of e-learning as a luxury and fun, lack of awareness of the foundations of the system, weak awareness of the importance of some department heads and the refusal to activate e-learning and finally some faculty members consider e-learning system is just win but there are other administrative obstacles such as lack of support from the Scientific Section. The author suggested activating the management systems of e-learning in teaching, especially the system of bridges to featuring its advantages.

\section{Cloud Computing Educational Environment}

Cloud computing is a rapidly growing subject that attracts many people from different disciplines. It transforms how computing resources (e.g. storage, servers, processing, networking and applications) are provisioned, managed and delivered to users $[3,5,19,46,47]$. The National Institute of Standards and Technology (NIST) defined five essential characteristics for cloud computing which include: On-demand Self Service, Broad Network Access, Resource Pooling, Rapid Elasticity and Measured Services [48-50]. Cloud providers may offer tremendous applications to their customers. These applications may vary widely to provide many services in education, government, banking and healthcare. The hardware and systems software in the datacenters that deliver those services is what we call a Cloud [3]. Users of cloud applications do not require expertise and knowledge to control the infrastructure segment of clouds, so abstraction and virtualization [51-54] might be provided to utilize the services of an 
Internet with high scalability, higher throughput, quality of service and high computing power, this is known as Infrastructure as a Service (IaaS). Cloud computing providers deliver common online services which are accessed on the Internet through a web browser. These services have long been referred to as Software as a Service (SaaS). The service being sold is called Utility Computing. Thus, Cloud Computing is the sum of SaaS and Utility Computing [5]. Cloud allows consumers to not only deploy but also design, model, develop and test applications directly on the Cloud. It supports work in groups on collaborative projects where project team members are geographically distributed, this is known as Platform as a Service (PaaS). PaaS provides development infrastructure including tools and programming languages. The cloud can be used by public individuals (public cloud), a single organization (private cloud) or more than one organization that share the same interests and policies (community cloud). It can also be a mixture of public and private clouds (hybrid cloud) $[55,56]$.

One of the most interesting applications of cloud computing is educational cloud [22,35,37,39]. The educational cloud computing can focus the power of thousands of computers on one problem, allowing researchers search and find models and make discoveries faster than ever and assist build a smarter planet. The universities can also open their technology infrastructures to private, public sectors for research advancements. The efficiencies of cloud computing can help universities keep pace with ever-growing resource requirements and energy costs [8]. Students expect their personal mobile devices to connect to campus services for education. Faculty members are asking for efficient access and flexibility when integrating technology into their classes. Researchers want instant access to high performance computing services, without the responsibility of managing a large server and storage farm. Educational cloud computing services represent a growing variety of useful services available on the internet and the most innovative and rapidly developing portion of the technology and education. It also promises to provide a variety of services that will be very useful to faculty, staff and students [11]. The role of cloud computing at university education should not be underestimated as it can provide important gains in offering direct access to a wide range of different academic resources, research applications and educational tools [12]. Educational cloud computing is quickly taking the education community by storm as more platforms, applications and services are being developed for academic cloud computing. Some students and researchers are already using a type of cloud computing based applications and services. Furthermore, these applications are heavily investing in cloud computing as the future of the academic learning and research [13].

There are many different cloud computing platforms for education in use nowadays. Justin et al. [1] has proposed Seattle - an educational networking, free, portable, and lightweight platform using donated cloud computing. Seattle allows students to learn the concepts of networking and distributed systems on computers spread through the Internet. Seattle can also emulate cloud computing, peer-to-peer computing and classify computing within a simple area. Computers running Seattle are protected from malicious and misbehaving code, making it safe to contribute resources from multiuse computers. Seattle has resources available for academics to use on about a thousand computers worldwide. Al Noor et al. [4] has proposed an architecture of cloud computing for education on the availability of widespread resources to all around Bangladesh. This architecture simply gives an effective and flexible way to match the resources with the current economical condition by utilization of unused resources and abstraction of third party involvements. It also provides a more flexible environment so that the client can also configure his own security policy. Sultan [16] has demonstrated how institutions and universities are likely to embrace cloud computing as many of them are bound to suffer from under-funding due to the global economic crisis. In conclusion educational cloud computing environment offers a wide range of services in application, platform, and infrastructure levels to students, faculty, researchers, and academic staff. 


\section{Case Studies}

The trend of educational cloud computing has been adopted by many leading IT companies. Microsoft software and services strategy are about the power of choice-a hybrid model of resources that enables the students and researcher to move as much or as little as they want to the cloud. Google Apps education in cloud computing is available at no cost to colleges, universities and educationally focused groups. Amazon Web Service has provided the universities and institutions of all sizes with an infrastructure web services platform in the educational cloud. The IBM Cloud Academy provides an application for educational institutions that are actively integrating IBM cloud computing technologies into their infrastructures for production and technical projects. HP Cloud provides an ecosystem of thought leaders who can share best practices, ideas and technology around the design and use of cloud computing capabilities for education. The following are case studies for educational clouds provided by the most popular cloud providers.

\subsection{Microsoft Education Cloud}

The Microsoft educational cloud enables researchers to flow workloads across the infrastructures and complement their existing IT assets with Web-based services [17]. Microsoft cloud services for education offers great programs such as Microsoft Live@edu at no cost to education accounts. Additionally, all services offer greater financial flexibility to educational institutions and enable lower costs to develop, scale, operate and migrate the systems that are distributed between the cloud and the datacenter [14]. The workplace is changing and the desktop applications that researchers and students use today will evolve to desktop applications combined with technical services. Moreover, Educators prepare workforce to partner with Microsoft for example, that can give them affordable access to those tools. Microsoft Live@edu is an application that provides students, researchers, staff, faculty with long-term, primary email addresses and other applications that can offer flexibility, collaboration and online communication all at no cost to education institutions. Figure 1 shows features of Microsoft Live@edu.

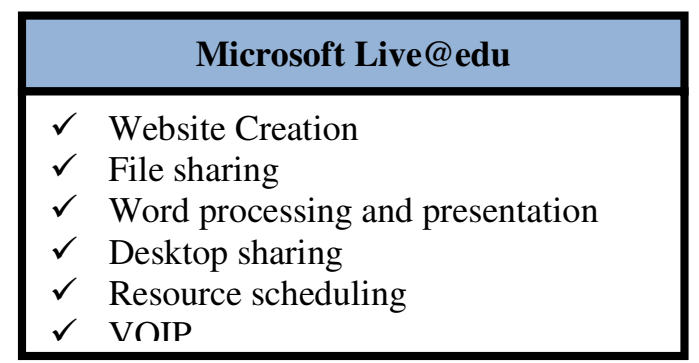

Figure 1: Features of Microsoft Live@edu

Microsoft products will be used by the students similar to those used in many workplaces that assist to prepare them for jobs after college [18]. Thus, Microsoft education cloud computing considers the following needs:

- Instant Message, Email and Educational Calendar

- Academic productivity such as document sharing and creation

- Flexibility and collaboration

- On demand resources for free

- Identity and relationship management

- Coordinating collaborative program development projects that consists of multiple departments

- Creating applications that can be shared by many students simultaneously

- Developing social networks or communities according to grade, school, or study area 
- Porting on-premise, line-of-education software to the cloud

- Testing Web services quickly

- Providing Mashups of data to meet accountability and assessment needs

- Hosting public web sites

- Evaluating risk and making informed decisions about the use of educational cloud computing.

- Testing and deploying large-scale applications in different environment

Microsoft's cloud computing solution is also called Windows Azure [36], an operating system that permits institutions, schools and universities to run Windows applications and stores data by Microsoft server. Moreover, the Azure Services Platform (ASP) are basically offered as services that allow the students and researchers to establish user identities, manage workflows, execute other functions such as Microsoft's online computing platform. Figure 2 shown below illustrates the different key components of ASP.

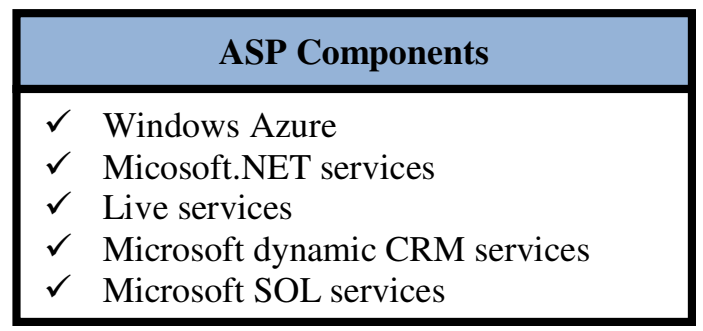

Figure 2: Key components of ASP

\subsection{Google Education Cloud}

Google Apps Education (GAE) in cloud computing available at no cost to colleges, universities and educationally focused groups. GAE includes the following applications: Google Mail (also known as Gmail), Google Sites, Google Video for education, Google Calendar, Google Talk and Google Docs Package (Documents, Spreadsheets and Presentations) allow workflow to proceed seamlessly among different types of documents. Each of these applications is entirely web-based, although there are client applications that supply additional functionality. Because all of these applications are web-based, each Google App is inherently cross platform; a modern cloud computing web browser might be supported by the computing platform to provide compatibility, scalability and essentially virtualized models [20]. Google Apps generally sets the standard for cloud computing interoperability; each App was designed to interoperate with the suite of Google's offerings. The GAE suites [21] include the following apps:

Google Mail: one of the key components to Google Apps is Google Mail, also called Gmail which are administered by the organization's IT administrator in the institution, schools and universities. It has $7 \mathrm{~GB}$ of storage per user, built-in chat, and IMAP capability that frees students from concerns about email quotas or spam.

Google Sites: easy-to-use web publishing tools let students on campus create and publish information and media, without having to learn any programming languages.

Google Video: provides secure and private video sharing for faculty and students.

Google Calendar: is a shared calendar management that puts everyone on campus "on the same page" when it comes to organizing schedules.

Google Talk: is the instant messaging (IM) component of Google Apps. IM is helpful for immediate, limited conversation with a colleague in a remote location in the classroom.

Google Docs Package: a real-time collaboration on documents, spreadsheets, and presentations that lets researchers and students work together across campus or around the world.

As a goal of replacing old application hosting solution with an outsourced hosting solution for students, the transition to Google Apps has been very productive. In general, students, 
researchers and faculty are very satisfied with the variety and consistency of service offerings. It is also best viewed as one of a suite of tools that campus IT can provide to its students and faculty. Because of the low cost factor, Google Apps are used as a supplementary technology and as the primary technology for any or all of its applications. The cost savings of implementing Google Apps to replace a student application server and a desktop office suite are huge. Although the cost is extremely competitive with some educational cloud computing, GAE is a clear choice which is considered a success at some universities and institutions around the world and is recommended as a complement to or a replacement for existing collaboration and communication systems which may already be in place. Table 1 illustrates the features of GAE as an education edition.

Table 1: Features of GAE

\begin{tabular}{|l|l|}
\hline Feature & Education Edition \\
\hline \hline Support & Phone support; 24 hours \\
\hline Service 1 & Resource scheduling \\
\hline Service 2 & 3rd party applications \\
\hline Service 3 & Google Video \\
\hline Cost & Free \\
\hline Storage & Same storage space as gmail.com \\
\hline Users & No limit \\
\hline
\end{tabular}

\subsection{Amazon Web Services (AWS) Cloud}

AWS has provided the universities and institutions of all sizes with an infrastructure web services platform in the educational cloud. With AWS students, researchers and faculty can requisition compute power, storage, number of users and other services-obtaining access to a suite of elastic IT infrastructure services as an education demand. With AWS, students, researchers, and faculty have the flexibility to select whichever development service or model of programming makes the most sense for finding the solutions for any problem. With AWS, they can take advantage of Amazon global computing infrastructure that is the backbone of Amazon multi-billion retail business and transactional enterprise whose scalable, flexible, reliable, and secure distributed computing infrastructure has been ameliorated for over a decade [24]. AWS provides a variety of benefits for educational institutions, IT organizations and developers alike as the following:

- Flexible: to build any application, control the resources and fit them into any application using any platform or any programming model.

- Comprehensive: The AWS gives a number of services that students, researchers and faculty can incorporate into them to develop applications.

- Dependable: The AWS cloud is a distributed, secure, resilient, reliable, and massively scalable.

AWS enables the academic community to inexpensively and rapidly build on global computing infrastructure to seek course material such as projects and intensify their productivity and results of research, while enjoying the same benefits of flexibility, reliability, elasticity, and cost effectiveness used by industry. The AWS in Education program provides [24, 25, 26, 28]:

- Access to selected course content resources

- Teaching Grants for faculty based on AWS

- Research Grants for academic researchers using AWS in their work

- Project Grants for student organizations pursuing entrepreneurial endeavours

- Tutorials for students that want to use AWS for self-directed learning

- Solutions for institution administrators looking to use educational cloud computing to provide efficient and cost-effective services in the institution's IT Infrastructure (figure 3). 
- AWS also manages the infrastructure that enables students, researchers and faculty to deploy highly scalable and reliable IT solutions.

\begin{tabular}{|cl|}
\hline \multicolumn{2}{|c|}{ Efficient services of AWS } \\
\hline$\checkmark$ & No contracts \\
$\checkmark$ & No hidden fees \\
$\checkmark$ & Better economics \\
$\checkmark$ & Time management \\
$\checkmark$ & Better environment \\
\hline
\end{tabular}

Figure 3: Efficient and cost effective services of AWS

Although AWS consists of more than a collection of infrastructure services, educator can save time by incorporating compute, storage, database, messaging, payment and other services that will give educators a head start on delivering for their business. All AWS services can be used independently or deployed together to create a complete computing platform in the cloud. Some comprehensive cloud computing platforms of AWS are the following:

- Amazon CloudFront: is a web service that offers a high performance and globally distributed content delivery. The distribution stream content to the users can be easily generated with low latency, high data transfer speeds and no commitments.

- Amazon Elastic Compute Cloud (Amazon EC2): is a web service that generates resizable compute capacity in the educational cloud. Virtual Amazon EC2 environment can be generally defined to the educators with the operating system, services, databases and application platform stack required for hosted applications. Amazon EC2 also provides a full management console and APIs to manage the data resources. It presents a true virtual computing environment, allowing the educators to use web service interfaces for launching instances with a different of systems, load them into the environment with the custom application, manage the network's access permissions, and run the image using as many or few systems [27]. Some features of Amazon EC2 are illustrated in Figure 4.

- Virtual Computing Laboratory (VCL): is an open source implementation of a secure production level on-demand utility computing and services oriented technology for accessing wide-area to solutions based on virtualized resources including computational resources, storage and software. VCL pilots are implemented with a number of universities around the world. The VCL implementation [38] has most of the characteristics and functionalities and is considered desirable in an educational cloud computing. Functionally, it has a large intersection with Amazon Elastic Cloud [23].

\begin{tabular}{|ll|}
\hline \multicolumn{2}{|c|}{ Features of Amazon EC2 } \\
\hline$\checkmark$ & Flexible \\
$\checkmark$ & Elastic \\
$\checkmark$ & Completely controlled \\
$\checkmark$ & Inexpensive \\
$\checkmark$ & Secure \\
$\checkmark$ & Reliable \\
\hline
\end{tabular}

Figure 4: Features of Amazon EC2

\subsection{IBM Cloud Academy}

The benefit of IBM Cloud Academy form access to a broad portfolio of IBM cloud computing projects, offerings and services that are designed for education and learning. Their researchers can innovate on the next generation of cloud computing technologies. They can collaborate with 
peer member institutions, as well as with the IBM research and development community, to create new approaches and strategies to improve educational services through cloud computing. The higher educational institutions pursue cloud computing initiatives, develop skills and share best practices for reducing operating costs while improving quality and access to education. According to IBM: "Cloud computing makes it easier for those in the education environment such as students, faculty and administrators", to gain immediate access to a wide range of new educational resources and research software and tools [10]. IBM Cloud Academy members also can [9]:

- Implement IBM cloud technologies solutions for education based on our world-class cloud technology for public and private clouds.

- Participate cloud services and technologies for IBM faculty, researchers, developers and partners in the definition of emerging cloud technologies.

- Collaborate with peers and developers-work with colleagues from around the globe in an accessible cloud-based collaboration forum to share good practices, ideas and insights.

The IBM solution divides IT workloads with many different services that make implementation and development easier. This gives academic institutions and universities an accessible indication for transitioning campuses over to the cloud. Each of these services is powered by IBM techniques and results in new benefits such as connecting and empowering the academic life [31]. Some IBM cloud education services are:

- IBM LotusLive collaboration: LotusLive offers easy-to-use communication and collaboration tools that connect students, colleagues, researchers and administrative staff for collaborative learning inside or outside campus. Silanis and IBM have joined together to integrate e-SignLive with Lotus-Live. These cloud computing services enable students, researchers and faculty to electronically sign document deals, legal contracts and other documents over the internet to reduce the time and cost [31,32].

- Virtual Computing Lab (VCL) education solution: VCL provides open source software and a technical infrastructure trim for the needs of educational institutions. VCL provides solutions for many problems such as reduced cost, increased power cuts, application contention and the demand for learning software.

- IBM Smart Analytics system: delivers query response times that are faster and better in quality than old systems and a single source of secure data for intelligence workloads.

- IBM Smart Business desktop cloud: allows virtualized schools and universities access environment. Thin clients and Internet devices have full access to platform independent, hosted applications and full client images.

\subsection{IBM and Google University Academic Initiative}

Google and IBM brings together with an initiative to advance large-scale distributed cloud computing by providing hardware, software, and services to schools, institutions and universities . This initiative allows students to use the potential of modern computing systems and the companies will provide them with hardware, software and services to advance training in large-scale distributed cloud computing. The aim of this initiative is to reduce the cost of distributed computing research, thereby enabling academic institutions and their students to more easily contribute to this emerging computing paradigm. As part of the initiative, a cluster of several hundred computers are generally provided by IBM and Google to surpass 1,600 processors. The Linux-based servers simultaneously run open source software virtualization system and Hadoop [29].

\subsection{Salesforce.com Education Cloud Platform}

The Salesforce.com platform provides all the tools needed for the educational institutions to instant scalability, ease of configuration and support for multiple functional roles. It enables comprehensive oversight of operations and applications allowing students, researchers and 
faculty to track, analyze and refine every aspect of their efforts. The Salesforce.com platform can also assists educators manage their services more efficiently from application to graduation while tracking individual details such as study abroad term, participation in campus organizations, study groups and other operations [34]. This platform can also share and mobilize information about students cross functionally between academic departments and housing. It can also support services to enhance the educational experience and support student success. The Salesforce Foundation's products provide faculty with the opportunity to organize information in a way that allows the alumni, admissions and our student advisors to effectively carry out their responsibilities. This direct development is critical to support the leadership in interdisciplinary research, urban engagement and the integration of classroom learning with real-world experience [33]. Services provided by Salesforce cloud for Education includes: Constituent Relationship, Alumni Advancement, Student Recruiting, Knowledge Management, Alumni and Applicant Portals, Student Retention, Faculty Collaboration, Student Tracking, and Study Abroad.

\subsection{ZMANDA Application for Education}

Zmanda has built a solid business providing added functionality and top-notch support to popular open source projects such as Amanda Open Source Backup and Archiving software for educators. Backup and recovery solutions have been focused to several products such as Amanda Enterprise, Zmanda Recovery Manager for MySQL and Zmanda Internet Backup. Zmanda now offers an alternative to traditional storage, backup and retrieve the data based on Amazon Web Services and Zmanda Internet Backup [40]. Moreover, Zmanda launched the Amazon S3 backup solution to educational organizations. Existing AWS customers are also among those to quickly see value in Zmanda's new offering. SmugMug (http://www.smugmug.com/) is one of the most known Internet photo-sharing sites, recently purchased Amanda Enterprise.

\subsection{HP Cloud Computing}

Automated system and hybrid service delivery management, combining the security of the private cloud with the convenience and cost-effectiveness of the public version, the result is a complete cloud solution that's prepared to fulfil the promise of "cloud driven" services and revenue for enterprises and service providers alike. HP Cloud System is the product of HP's experience in delivering industry and education-leading automation, application management, and converged infrastructure capabilities. It enables clients such as students, faculty and researchers to build, manage, and consume cloud services across private clouds, public clouds, and traditional IT environments-without having to know, or care, whether those services come from HP Cloud System's own "on premises" resources or from the public domain [41]. HP Cloud System is the only singular platform system that provides a lot of applications and services from an extensive range of sources and easily scales on demand. It's a complete cloud system that integrates the control and delivery of cloud assets whether their provenance is the datacenter, an HP hosted cloud, or an external source such as Amazon EC2 services. With HP Cloud System, students, faculty and researchers get a single, seamless cloud solution that:

- Manages and delivers End-to-End automated application

- Unifies and controls self-service portal with a built in service catalog

- Completes lifecycle management

- Tracks the development of a cloud service catalog

- Supports for multiple departments and clients such as students, faculty and researchers

- Provides scalability and one-click, just in time provisioning

- Innovates open standards to support multiple types of applications

- Provides security, privacy and compliance

Students, faculty and researchers can add mission critical computing with HP and heterogeneous management of their existing environment with HP Software. In addition, the HP 
cloud solution is designed to help educators develop and implement their hybrid cloud services. The core cloud system consists of the followings:

- HP BladeSystem Matrix: delivers an automated, common modular architecture that can provision physical resources, virtual infrastructure and applications

- HP Cloud Service Automation software: includes a template designer for cloud services, along with a common self-service portal

- Cloud Maps: can track the creation of a cloud service and application catalog

- HP Storage: a utility to storage technology that can deliver virtually unlimited tiered storage capacity

- HP Security Point: the main purpose of this point is to secure, detect and protect spanning applications as well as cloud, virtual, and physical infrastructures

- HP Networking: provides high-performance, flexible networking from edge to core

- Mission-Critical Computing: with solutions such as HP BladeSystem Matrix

\section{Challenges to Cloud Education}

Cloud computing is a new model which is threatening by some individuals in universities and institutions. It challenges computing service personnel who may fear the consequences of their roles being outsourced. In addition, some developers might feel uncomfortable about transferring business-critical data and services outside the institution. Thus, some challenges may be more to do with perception than reality [30]. These challenges include:

1) Security threats: A major obstacle to cloud computing is the security threats including tampering or leakage of sensitive data on the cloud, loss of privacy and the unauthorized use of the data by cloud providers [62-67]. Hence, a number of security requirements should be satisfied by educational cloud computing systems to protect data from these threats $[55,56]$. These requirements are [68]:

Identification and Authentication: cloud service providers should establish accounts for faculty, students, and staff who should be individually verified and validated by employing usernames and passwords to protect their profiles on the cloud.

$>$ Authorization: priorities, permissions and resource ownerships on the cloud should be controlled. Each individual of faculty, staff, or students in the institution is granted privileges based on his account.

$>$ Integrity and Confidentiality: encryption techniques should be employed to protect sensitive data of institution such as exams, grades, etc from tampering or unauthorized access.

$>$ Non-repudiation: ensure that institution's transaction send and receive transfer cannot be denied. Techniques such as digital signatures, timestamps and confirmation receipt services can be deployed in educational cloud to achieve non-repudiation.

$>$ Availability: means that the data will be available, accessible and obtainable at all times on the educational cloud. Denial of Service (DoS) is a great source of threats. It has been suggested that the supply of cloud services through one provider is a single point of failure and that contract will be available for more than one cloud provider in order to minimize risk.

2) Lock-in: Google and Microsoft allow institutions to cooperate their cloud products. There may be a risk in associating an institution too closely with these companies whose popularity is variable with students, researchers or faculty. Probably of greater risk, however, is that universities and institutions will become "locked-in" to the products of specific provider. There are significant costs in migrating from any widely used system. Institutions which start to integrate educational processes with the cloud systems will find it even more difficult to test, deploy and integrate. 
3) Unsolicited Advertising: Cloud providers will focus on users with unsolicited advertising. The accumulation of usage data by the providers may be of value for onward selling to third parties, though it may be anonymized. The inclusion of appropriate clauses in the contract may minimize the risk of abuse.

\section{CONCLUSIONS AND Future WORK}

The population in Saudi Arabia is growing very fast and the Saudi Arabian government has mandated universities in the Kingdom to provide an education to all citizens. Saudi government has made a lot of effort to enhance educational system over the last five years by introducing development initiatives and building numerous universities. Therefore, the Ministry of Higher Education (MOHE) works to create, regulate, and enforce law penetrating the higher education system in KSA. According to Saudi higher education ministry, the current number of the students in Saudi universities is about a million students this year. The LMS/CMS is an elearning platform which is considered as an important part of e-learning solutions from the university's viewpoint but LMS is software that automates the administration of training events. This paper presents educational cloud computing as a new trend for e-learning in KSA and shows how universities and institutions can take advantage of the cloud not only in terms of cost but also efficiency, security, reliability and portability. Several examples of cloud computing in education such as Microsoft, Google App, IBM, Amazon and others were provided and a case study of the applications was presented and explored in more details. The future challenges to this new trend including problems and risks have been also discussed. We believe that cloud computing opens a new era in education and e-learning because it provides a flexible, costeffective and efficient infrastructure that universities and institutions can deploy to allow their faculty, staff and students accomplish their work better and faster than ever.

The MOEH in KSA sent a lot of students to complete their $\mathrm{PhD}$ in e-learning and cloud computing in development countries such as UK, USA and Australia due to the great lack of professional development in faculty. A recommender system in e-learning context which is a software agent that tries to "intelligently" recommend actions to a learner based on the actions of previous learners is required especially when we use the cloud education system. The required framework for building automatic recommendations in e-learning platforms which is composed of two modules: an off-line module which pre-processes data to build learner and content models and an online module which uses these models on-the-fly to recognize the students' needs and goals is required to be a part of cloud computing education system. Finally some experts in planning academic programs using e-learning stated that there is almost no professional support base for e-learning at the moment and indeed, educational theory or design is not a topic taught in the universities in KSA. There are educational technology departments, but their focus appears to be on media studies and production. Therefore, a great deal of training for e-learning will need to come from outside and we consider cloud computing education system is promised in KSA because there are financial supports, government commitment and subtle pressure from women faculty for change. The study presented in this paper helps the leadership and decision makers improve education and provides advises to educational institutions and individuals on the tremendous applications and services available in the cloud.

\section{REFERENCES}

[1] Justin, C., Ivan, B., Arvind, K. and Tom, A. "Seattle: A Platform for Educational Cloud Computing" SIGCSE09, March 37, 2009, Chattanooga, Tennessee, USA. 2009.

[2] Shanthi Bala, P. "Intensification of educational cloud computing and crisis of data security in public clouds", International Journal on Computer Science and Engineering (IJCSE), Vol. 02, No. 03, 2010, 741-745. 
[3] M. Armbrust, A. Fox, R. Griffith, A. Joseph, R. Katz, A. Konwinski, G. Lee, D. Patterson, A. Rabkin, I. Stoica, and M. Zaharia, "Above the Clouds: A Berkeley View of Cloud Computing," UC Berkeley Reliable Adaptive Distributed Systems Laboratory, 2009.

[4] Al Noor, S., Mustafa, G., Chowdhury, S., Hossain, Z. and Jaigirdar, F. "A Proposed Architecture of Cloud Computing for Education System in Bangladesh and the Impact on Current Education System" International Journal of Computer Science and Network Security (IJCSNS), Vol.10 No.10. 2010.

[5] L. Vaquero, L. Rodero-Merino, J. Caceres, and M. Lindner, "A Break in the Clouds: Towards a Cloud Definition," ACM SIGCOMM Computer Communication Review, Volume 39 Issue 1, pages 50-55, January 2009.

[6] Cloud Computing Articles. Cloud Computing Education. http://www.code2cloud.com/cloudcomputing-education/

[7] Cloud Computing Articles, SaaS+PaaS+IaaS. Free Cloud Apps for Educational Institutes: Schools, Colleges, Universities. http://www.techno-pulse.com/2010/08/free-cloud-apps-educational-institutes.html

[8] IBM Academic Initiative. Cloud computing: Delivering Internet-based information and technology services in real time. https://www.ibm.com/developerworks/university/cloud/

[9] IBM Sales and Distribution, Solution Brief for Education. IBM Cloud Academy Education for a smarter planet. ftp://ftp.software.ibm.com/common/ssi/ecm/en/eds03007usen/EDS03007USEN.PDF

[10] CJB, R. and Evans, N. "A proposal for the Adoption and use of cloud computing in secondary education in South Africa". 11th DIS Annual Conference 2010, 2-3 September, Richardsbay, University of Zululand, South Africa

[11] Cloud Computing Services: Appropriate use of online software tools such as Google Apps, Gmail, and Microsoft Live Office by the Michigan State University Community, http://lct.msu.edu/documents/CloudComputingatMSU,guidancedocument,6Sep2011.pdf

[12] Youry, K. and Volodymyr, V. "Cloud Computing Infrastructure Prototype for University Education and Research", WCCCE'10, May 78, 2010, Kelowna, Canada.

[13] Grimes, M., Jaeger, T., and Lin, J. "Weathering the Storm: The Policy Implications of Cloud Computing. iConference", 2009.

[14] Microsoft, Education all in. Cloud Computing from Microsoft - Empowering Education through Choice.http://www.techrepublic.com/whitepapers/cloud-computing-from-microsoft-empoweringeducation-through-choice/3333523

[15] Thomas, P. "Cloud Computing: A potential paradigm for practising the scholarship of teaching and learning”, Electronic Library, The, Vol. 29 Iss: 2, pp.214 - 224, 2011.

[16] Sultan, N. “Cloud computing for education: A new dawn?”, International Journal of Information Management 30 (2010) 109116.

[17] Microsoft, Cloud Computing Web Site. Cloud Computing in Education. http://www.microsoft.com/education/en-us/solutions/Pages/cloud_computing.aspx

[18] A Microsoft U.S. Education white paper. Cloud computing in education Savings, flexibility, and choice for IT. http://www.microsoft.com/educloud/

[19] Toby, V., Anthony, V. and Robert, E. "Cloud Computing, A Practical Approach", ISBN-13: 978-007-162694-1, 353 Pages. 2009.

[20] Herrick, R. "Google This! Using Google Apps for Collaboration and Productivity", SIGUCCS09, October 11-14, 2009, St. Louis, Missouri, USA. 
[21] Google Apps Education Edition: communication, collaboration, and security in the cloud. http://www.google.com/a/edu/

[22] "How can cloud computing help in education", http://www.cloudtweaks.com/2011/02/how-cancloud-computing-help-in-education/, 2001

[23] Vouk, A. Cloud Computing Issues, Research and Implementations. Journal of Computing and Information Technology - CIT 16, 2008, 4, 235246, doi:10.2498/cit.10013912008.

[24] Amazon Web Services (AWS) Web Site. What is AWS? A comprehensive cloud computing platform. http://aws.amazon.com/what-is-aws/

[25] Amazon Web Services, Case Study. Application Hosting.

http://aws.amazon.com/solutions/case-studies/

[26] Amazon Web Services, Educator. AWS in Education. http://aws.amazon.com/education/

[27] Amazon Web Services (AWS), EC2 Web Site. Amazon Elastic Compute Cloud (Amazon EC2). http://aws.amazon.com/ec2/

[28] AWS Case Study: Educations.com, Web Site AWS Case Study: Educations.com. http://aws.amazon.com/solutions/case-studies/educations-com/

[29] Jiabin, D. Virtualization, Application Streaming and Private Cloud Computing in a Training Laboratory. Journal of software, vol. 5, no. 11, doi:10.4304/jsw.5.11.1306-1313 2010.

[30] Sclater, N. "cloud computing in education: policy brief", UNESCO Institute for Information Technologies in Education. 2010. http://unesdoc.unesco.org/images/0019/001904/190432e.pdf

[31] Cloud-onomics in education, IBM Cloud Academy, Web Site. Cloud 9: Future Compatible Computing in Education. http://www.ibm.com/ibm/files/T641866T23726I58/EBE03001USEN.PDF

[32] Silanis e-SignLive Services. Software-as-a-Service (SaaS) e-Signature Service. http://www.e-signlive.com/blog/tag/software-as-a-service/

[33] Salesforce.com foundation, Higher Education Solution. Taking higher education to a higher level. http://www.salesforcefoundation.org/products/discounts/higher-ed/

[34] Salesforce.com foundation, Higher Education. The Real-Time Cloud for Higher Education. http://www.salesforcefoundation.org/products/higher_education_solution/

[35] Dan Morill, “Cloud Computing in Education”, http://www.cloudave.com/14857/cloud-computingin-education/, 2011.

[36] Microsoft News Center. Windows Azure and the Azure Services Platform: Making Microsofts Software-plus-Services Vision a Reality. http://www.microsoft.com/presspass/features/2008/oct08/1027pdcfeature1.mspx/

[37] Marinela M. and Anca A. "Using Cloud Computing in Higher Education: A Strategy to Improve Agility in the Current Financial Crisis", 2011.

http://www.ibimapublishing.com/journals/CIBIMA/2011/875547/875547.pdf

[38] VCL Web Site. VCL Conceptual Overview Diagram. https://cwiki.apache.org/VCL/

[39] John P. "Cloud computing - what is it and what does it mean for education?" http://erevolution.jiscinvolve.org/wp/files/2009/07/clouds-johnpowell.pdf 
Advanced Computing: An International Journal ( ACIJ ), Vol.3, No.1, January 2012

[40] Zmanda. Zmanda Application. http://www.zmanda.com/amanda-enterprise-edition.html

[41] HP cloud system. A single platform for private, public, and hybrid clouds. Simply the most complete cloud system for enterprises and service providers. Hewlett-Packard Development Company 2011.

http://www.hp.com/hpinfo/newsroom/press_kits/2011/EBcloudcomputing2011/fs_Cloud_CloudSystem.p df.

[42] Ellen Wagner, "Delivering on the promise of e-learning", white paper, http://www.adobe.com/education/pdf/elearning/Promise_of_eLearning_wp_final.pdf

[43] Luciana Carabaneanu, Romica Trandafir, and Ion Mierlus-Mazilu, "Trends in e-learning", http://www.codewitz.net/papers/MMT_106-111_Trends_in_E-Learning.pdf

[44] Som Naidu, "E-learning a guidebook of principles, procedures and practices", CEMCA, 2006.

[45] "What is Electronic Learning", http://www.mup.com.au/uploads/files/pdf/978-0-522-85130-4.pdf

[46] Michael Miller, "Cloud Computing Pros and Cons for End Users", microsoftpartnercommunity.co.uk, 2009. http://www.informit.com/articles/article.aspx?p=1324280

[47] http://en.wikipedia.org/wiki/Cloud_computing

[48] GTSI Group, “Cloud Computing - Building a Framework for Successful Transition,” White Paper, GTSI Corporation, 2009.

[49] T. Dillon, C. Wu and E. Chang, "Cloud Computing: Issues and Challenges", 24th IEEE International Conference on Advanced Information Networking and Appications, 2010.

[50] P. Mell and T. Grance, “The NIST Definition of Cloud Computing” Recommendation of NIST, 2011

[51] Cloud Computing vs. Virtualization http://www.learncomputer.com/cloud-computing-vsvirtualization/

[52] Wikipedia , http://en.wikipedia.org/wiki/Virtualization

[53] Y. Luo,"Network I/O Virtualization for Cloud Computing",IEEE Computer Society,Oct. 2010.

[54] V. Sarathy, P. Narayan, and R. Mikkilineni, "Next generation Cloud Computing Architecture" 2nd International IEEE Workshop On collaboration \& Cloud Computing, 2010.

[55] N. Robinson, L. Valeri, J. Cave, T. Starkey, H. Graux, S. Creese and P. Hopkins, "The Cloud Understanding the Security, Privacy and Trust Challenges”, RAND Corporation, 2011.

[56] W. Jansen and T.Grance "Guidelines on Security and Privacy in Public Cloud Computing", NIST Draft Special Publication 800-144, 2011.

[57] Mohammed Saleh Albalawi, Critical Factors Related To The Implementation Of Web-Based Instruction By Higher-Education Faculty At Three Universities In The Kingdom Of Saudi Arabia”, PhD thesis from Department of Instructional and Performance Technology College of Professional Studies The University of West Florida, 2007

[58] Mirza, A., "Is E-Learning Finally Gaining Legitimacy in Saudi Arabia?", Saudi Computer Journal, Vol. 6, No. 2, 2007.

[59] Kamla Ali Al-Busaidi and Hafedh Al-Shihi, "Instructors' Acceptance of Learning Management Systems: A Theoretical Framework", IBIMA Publishing, Communications of the IBIMA, Vol. 2010, Article ID 862128, 10 pages, http://www.ibimapublishing.com/journals/CIBIMA/cibima.html 
Advanced Computing: An International Journal ( ACIJ ), Vol.3, No.1, January 2012

[60] Hend S. Al-Khalifa, “A First Step in Evaluating the Usability of JUSUR Learning Management System", The 3rd Annual forum on E-learning Excellence Bringing Global Quality to a Local Context, Dubai UAE , from 1-3 February 2010, ISBN 978-9948-15-396-2

[61] Hisham B. Hussein, "Attitudes Of Saudi Universities Faculty Member Toward Using Learning Management System (Jusur)”, The 2011 New Orleans International Academic Conference, New Orleans, Louisiana USA 2011.

[62] "Cloud Computing Security Considerations", Cyber Security Operation Cenetre, Technical report, 2011.

[63] I. Chuang, S. Li, K. Huang, and Y. Kuo, "An effective privacy protection scheme for cloud computing", In Proceeding of the 13th International Conference on Advanced Communication Technology (ICACT), 2011

[64] C. Wang, Q. Wang, K. Ren, and W .Lou, "Towards Secure and Dependable Storage Services in Cloud Computing", IEEE Transactions on Services Computing, Issue:99 , 2011.

[65] Q. Wang, C. Wang, K. Ren W. Lou, and J. Li, “Enabling Public Auditability and Data Dynamics for Storage Security in Cloud Computing" IEEE Transactions on Parallel and Distributed Systems, Volume : 22, Issue:5, 2011.

[66] C. Ba $\square$ sescu, A. Carpen-Amarie, C.Leordeanu, A. Costan, and G. Antoniu, "Managing Data Access on Clouds: A Generic Framework for Enforcing Security Policies", In proceeding of IEEE International Conference on Advanced Information Networking and Applications (AINA), 2011

[67] R. Sravan Kumar and A. Saxena, "Data integrity proofs in cloud storage", Third International Conference on Communication Systems and Networks (COMSNETS), 2011.

[68] Ramgovind S, Eloff MM and Smith E. "The Management of Security in Cloud Computing" Information Security for South Africa (ISSA), Sandton, Johannesburg, 2-4 Aug, 2010. 